\title{
Figuras de linguagem na comunicação: a imagem de homens de dinheiro e homens sem nada na comédia Cidadão Zero do Arquivo Miroel Silveira
}

Andrea Limberto Leite

\section{Resumo:}

Dentre os processos de censura prévia ao teatro do Arquivo Miroel Silveira, analisaremos o caso da comédia Cidadão Zero, de Gastão Pereira da Silva, considerando a Retórica das Figuras e a Análise de Discurso. Pensamos a construção de figuras de linguagem no cerne dos processos de comunicação, como produção de efeitos de sentido e como possibilidade de sustentar uma formação ideológica e estereotípica.

\section{Palavras Chave:}

Comunicação, censura, figuras de linguagem, estereótipos

\begin{abstract}
:
We analyze the censorship process over the theater comedy Cidadão Zero (Citzen Zero), written by Gastão Pereira da Silva and part of the Miroel Silveira Files. Our approach involves discourse analysis, rhetorical figures and the belief that figures of speech are in the core of communication dynamics, such as generate sense effects, and present ideological and stereotypical formations.
\end{abstract}

\section{Keywords:}

Communication, censorship, figures of speech, stereotypes

Temos como objeto os trechos censurados das peças parcialmente liberadas pertencentes ao Arquivo Miroel Silveira (AMS). Observaremos em tais trechos a presença de figuras de linguagem. É nessas figuras que acreditamos estar um desvio em relação ao percurso temático da peça teatral e acreditamos que nelas resida também um momento de produção de sentido.

Pensamos que as figuras de linguagem, como momento privilegiado da produção de sentido, nos revelam sobre ideologias. No caso, buscamos aquelas censuradas. O fato do censor cortar determinado trecho da peça teatral, marcando-o, nos encaminha para a busca de algo a mais presente ali. $\mathrm{O}$ estudo das figuras retóricas nos permite, ainda, pensar no desvio em relação a uma norma e na formação dos estereótipos e dos lugares comuns.

Na medida em que esse sentido é censurado, ele se torna relevante para nossa análise na busca de: um padrão temático-figurativo dos cortes, a relação entre a formação figurativa e o corte, uma catalogação dos sentidos censurados.

Neste trabalho trataremos especificamente da comédia Cidadão Zero, de autoria de Gastão Pereira da Silva, com pedido de censura do ano de 1954. Ela se desenvolve sobre o embate de duas imagens, da riqueza associada à desonestidade e da pobreza associada à honestidade.

Tratando-se de uma comédia, brinca-se com o que o público espera das personagens e dos ideais em jogo nas ações de cada uma. Aquilo que se imagina no início da peça ganha contornos inusitados até o final. São 
estabelecidas duas visões sobre quem seriam os miseráveis na sociedade. Há uma separação entre ladrões e homens honestos, endinheirados e pobres, trabalhadores e usurpadores.

Ressalta-se ainda que o presente trabalho está vinculado ao doutorado «Comunicação e Censura - análise do veto sobre figuras de linguagem nas obras teatrais do Arquivo Miroel Silveira» e ao eixo temático de pesquisa «O poder e a fala na cena paulista do Arquivo Miroel Silveira».

Analisando os cortes sobre os textos das peças teatrais, estudaremos uma lógica na ação da censura que se revela no veto, em seus pressupostos, vinculados a ideologias e estereótipos.

Através da análise de discurso, podemos entender a relação entre os diversos trechos censurados, propondo um recorte horizontal do arquivo pesquisado e conferindo unidade ao objeto de pesquisa. No que diz respeito às figuras de retórica, consideramos que podem ser o caminho de entrada para a análise, no contato direto e mais próximo com as peças. Poderíamos ressaltar que toda a linguagem tem um caráter de figuração, mas que em certos momentos ele é uma função dominante no texto.

Entendemos que as figuras de linguagem, por seu caráter argumentativo, são um importante fator de coesão textual. Assim, seu corte poderia comprometer os efeitos de sentido da obra e mesmo promover a desarticulação do texto ao limite de ser perdido em incompreensão.

Ressaltamos, dessa forma, a recuperação que se faz de informações sobre a história da arte teatral e das idéias em São Paulo e no Brasil, assim como sobre as relações de poder que se apresentam entrelaçadas nos trechos censurados.

A arte teatral tem especial interesse de estudo pois foi uma atividade de vanguarda e de influência na conformação de idéias em vários momentos do período coberto pelo AMS. Foi importante para São Paulo como forma de trazer idéias vindas do exterior e somá-las criativamente incorporando elementos de nossa cultura.

Para a área de comunicação, os achados advindos da presente pesquisa podem contribuir para um melhor entendimento dos processos que a norteiam, especialmente aqueles relacionados ao crivo sobre conteúdos a serem divulgados.

Dentro ainda do universo da análise de discurso, incluímos o presente estudo na área da Semântica do discurso. Por Semântica, entende-se o estudo do sentido, o projeto de perceber os mecanismos que regulam suas mudanças, caminhos e desvios. Discurso tem uma ampla gama de definições, desde a mais clássica, que é a colocação do aparato visual da língua na atualização da fala corrente, até uma unidade ampla o suficiente para conduzir a visão de mundo de um grupo social em determinada situação espaço-temporal. Nessa última acepção, discurso é tanto o nome dado às especialidades de conhecimento (Física, Matemática, Sociologia, etc.), quanto a uma posição político-ideológica (discurso dos direitos humanos, por exemplo).

Especialmente na acepção de discurso como posição político-ideológica, propomos que a censura atue em nível discursivo, incidindo sobre a difusão e a formação de novas confluências ideológicas.

Assim, dizemos que há uma lógica nos cortes promovidos. Propomos um caminho para investigá-los, através do que não é dito no texto da peça, mas que pode estar pressuposto nele. Pensamos, com Oswald Ducrot, que em todo dizer há um não-dito, que interfere no «como» se diz.

O que o censor não quer que seja dito? Qual é o não-dito importante para a situação encenada na peça? Podemos dizer que este é um trabalho que se pergunta pelo sentido do texto, tanto quanto pelo sentido da 
intervenção do censor.

\section{O Arquivo Miroel Silveira}

O Projeto Temático com financiamento FAPESP, «A cena paulista - um estudo da produção cultural de São Paulo entre 1930 e 1970 através do Arquivo Miroel Silveira da ECA-USP», foi outorgado em 2004 e, desde então, reúne pesquisadores de diversos níveis - desde bolsistas de iniciação científica, mestrado e doutorado a professores doutores, coordenadores de eixos temáticos de pesquisa. Ficou conhecido simplesmente como o Arquivo Miroel Silveira (AMS), vinculado à Biblioteca da ECA-USP.

Tal Arquivo não reúne trabalhos daquele que foi dramaturgo e professor da ECA, presta-lhe uma homenagem ao usar seu nome para o conjunto de 6.206 processos de liberação de peças teatrais para apresentação pública entre 1925 a 1972. O material é resultado da submissão e arquivamento das peças submetidas à apreciação do Departamento de Diversões Públicas de São Paulo (DDP-SP) no referido período, chegando à ECA com o fim da censura.

Conta com quatro eixos de pesquisa. $\mathrm{O}$ eixo de pesquisa «O Poder e a Fala na Cena Paulista», coordenado pela profa. Mayra Rodrigues Gomes, se concentra no estudo das peças parcialmente liberadas analisando os trechos censurados. Tal eixo de pesquisa parte da compreensão de que a Censura Prévia, que acompanhou o desenvolvimento do teatro em São Paulo, e em todo o Brasil, durante as décadas de 1930 a 1970, permite entender e detectar os processos de popularização das artes através das mídias e de acirramento das relações entre o estado e o teatro.

Entendemos como peças parcialmente liberadas aquelas que sofreram algum tipo de intervenção do censor, sem chegarem a ser totalmente vetadas ou totalmente liberadas. Dentre as peças do arquivo, contabilizamos cerca de 1.326 processos deste tipo. Exclui-se desta cifra aquelas que ainda estão em processo de catalogação.

As peças parcialmente liberadas apresentam diferentes graus de interferência do censor. Os cortes do censor podem variar da exclusão de palavras a mais de uma página completa da obra e dentre elas pelo menos tiveram palavras censuradas.

As parcialmente liberadas poderiam ainda ser restritas por lugar, idade ou público espectador. Mas as que nos interessam mais proximamente são aquelas com trechos cortados. Não só com uma palavra cortada, mas que nos corte se desenhe uma imagem. Consideramos que essa imagem pode estar composta no contexto da peça e que tenha a relação com o trecho não cortado. Aliás, é importante salientar que esta relação se faz sempre presente e é necessário observar o que foi cortado á luz daquilo que foi permitido ou não-cortado.

Analisaremos os trechos censurados tendo lido o texto completo da peça dentre as selecionadas para a amostra. Eles serão observados em sua formação de figuras de linguagem, na relação que essas mantém com o sentido geral do texto (dimensão diacrônica) e com o momento da peça em que se encontram (dimensão sincrônica).

\section{Figuras de linguagem}

Tendo em vista a análise das ocorrências textuais das figuras de linguagem, recorreremos à análise de discurso de linha francesa, procurando respaldo teórico essencialmente no trabalho de Oswald Ducrot e na Retórica das Figuras, recuperada da retórica clássica principalmente através dos trabalhos de Fontanier e Perelman. A análise de discurso, em conjunto com os estudos que recuperam a tradição retórica, denominados de nova retórica, fornecem um caminho metodológico. 
Essa combinação permitirá observar a formação das figuras de linguagem nos textos teatrais. A análise de discurso permitirá entender os mecanismos de construção de sentido, na formação de uma imagem, na referência a uma formação discursiva (estratos em Hjemslev, estratificação em Deleuze).

No caso específico das figuras de linguagem reconhecemos uma apropriação pela análise de discurso de categorias que se mantém inclusive na nomeação das figuras de linguagem. Há, atualmente, uma retomada dos estudos das figuras de linguagem através da lingüística e também através da nova retórica (com expoente em Chaïm Perelman). Vigora também o estudo retórico das narrativas.

Tendo em vista que a Retórica entende a produção do discurso como uma atividade destacada em relação a outras, podemos enxergar nesse ponto uma abertura para que esteja presente a concepção de que o objetivo do texto não é a reprodução fiel da realidade. Esse pode ser considerado um ponto de crítica contra a tradição Retórica e fonte do juízo de valor negativo que recai sobre ela. Considerando que o trabalho com o texto pode ser descolado das idéias mais concretas e descritivas, há abertura para criação e para a entrada de um ambiente mais figurativo ou podemos dizer ainda ficcional.

Entendemos a figura de linguagem como um segundo nível no trabalho com a linguagem: o primeiro deles é a própria entrada na esfera da linguagem (ou seja, o autor concebe o texto dramático) e ao invés de manter-se nesse nível ele realiza um salto poético, produzindo uma figura. Dessa forma ele agrega força dramática e chama atenção para a forma da criação de sentido no texto.

Uma figura de linguagem pode ser considerada ainda um modo desviado da maneira normal de dizer (regulado ou do senso comum). Conceituamos, ainda, de outra forma: as figuras de linguagem são a apresentação de uma associação de idéias inusitada, quebrando a expectativa do leitor/ouvinte. Ela é inusitada, mas ao mesmo tempo compreensível, de forma que joga com um ideário familiar ao seu público.

Nas figuras, as palavras devem estar em harmonia, acomodadas uma com as outras. Assim, analisar uma figura supõe investigação sobre a ordem e combinação de suas palavras, de suas partes. Deveria, então, haver uma ordem correta para as palavras, uma disposição apropriada. Mas quando há um desvio e ele é virtuoso, podemos considerá-lo como erro voluntário do poeta ou trovador. Ao ser considerado como tal, deve ser identificado seu fim como mérito de arte, estrangeirismo ou embelezamento. Não ocorre por ignorância. Considera-se que os critérios são fluídos e dependem de um juizo de valor. Um mesmo torneio na prosa pode ser erro e no verso uma figura.

Com Quintiliano, podemos dizer que o discurso figurado é aquele oblíquo em relação a seu fim. Essa obliquidade pode se encaminhar em processos que atualmente podemos definir como metafóricos ou metonímicos. Reconhecemos, nesse mecanismo, os dois eixos classificatórios das diversas figuras retóricas. Essa divisão, de inspiração em Jakobson, com raízes na lingüística saussuriana, é hoje aceita por pensadores de diversos campos do conhecimento e, por isso, dela nos valemos aqui. “(...) metáfora e metonímia são procedimentos discursivos de produção de constituição de sentido. Nelas o narrador rompe, de maneira calculada, as regras de combinatória das figuras, criando uma impertinência semântica, que produz novos sentidos." (Fiorin, 2006, p. 118)

Temos assim dois eixos principais para pensarmos as figuras de linguagem: a metáfora e a metonímia. Pensando que a metáfora tem como base a substituição de termos correlatos num eixo de sicnronia e a metonímia a associação de termos num eixo de contiguidade. A partir da relação entre pressupostos e subentendidos podemos associar a essas duas formas.

Podemos dizer que na metonímia há uma manutenção dos pressupostos já aguardados. Dessa forma, o enunciado não traz surpresa, mas reafirmação de posições sedimentadas. Sobre a metáfora, podemos dizer que 
há associação a um pressuposto novo. Ou ainda, soma-se o pressuposto esperado com um pressuposto que se associa inusitadamente.

Toda a figura de linguagem trabalha sobre pressupostos correntes pois ela depende deles para se criar sob pena de não ser compreendida (não fazer sentido). Ela figurativiza pressupostos. A figura mostra, cria uma imagem, então não a situamos no nível do subentendido (como pensado em Ducrot).

Tanto a metáfora como a metonímia apresentam abertura para o subentendido, fazendo com que o elemento a ser substituído seja apenas sugerido, mas não dito. Observamos que a combinação do uso de figura de linguagem com o recurso de subentender torna o enunciado obscuro, sendo mais rara.

As figuras de linguagem, por sua característica de cativar a adesão do público ao discurso, representam um caminho interessante para a análise dos pressupostos de uma época e/ou lugar. Estes últimos ganham contornos na ordenação do texto (elocução) e podem ainda ser combinados para comporem uma só figura.

\section{Cidadão Zero}

Trouxemos como exemplo a peça Cidadão Zero, uma comédia de autoria de Gastão Pereira da Silva, com pedido de censura de 1954 e que teve como parecer do censor a proibição para menores de 18 anos respeitados cortes das páginas 11 a 19 .

A peça mostra um ladrão incomum, que é o Cidadão Zero, que procura fazer justiça social à sua maneira, condenando a desonra moral daqueles que tem dinheiro. Debocha deles, afronta-os com fúria verbal e sem pudores. Tenta mostrar que estes são os verdadeiros miseráveis.

A peça sofreu dois cortes que identificamos como incidentes sobre figuras de linguagem. Ambos estão num momento em que os conflitos da peça já estão instaurados. Um dos cortes é sobre o momento de glória da personagem Cidadão Zero. Tal personagem é um tipo diferente de ladrão. Ele não está preocupado em garantir ganhos para si mesmo, mas quer fazer circular os bens para as mãos de outros. Ele rouba e coloca nas mãos de quem ele acha que seria justo. Então, após suas atuações vem o discurso que as define, que prova o argumento que vem conduzindo suas atitudes durante toda a peça.

\section{“Tompson: - Miserável!}

Cidadão: - Miserável deveria ser aqueles que aproveitam da miséria dos humildes para enriquecer. Miserável é o senhor que cumulou a sua fortuna com o esforço dos pequeninos...daqueles que arriscavam a vida pendurados nos andaimes... dos que descem às minas e que depois ficam cegos com o brilho do outro que circula no seu bolso... dos famintos que, de sol a sol, apunhalam as arvores para estrair a borracha dos seringais, mas que nunca sentiram o conforto macio das rodas dos grandes packards... dos que morrem intoxicados pelas tintas que ornamentam as paredes dos "boudoirs"... dos que recollhem o lixo que sobra da fartura de todos os arranha-céus... dos que cintilam nos dedos, como uma afronta impiedosa aos que não podem comer... dos que se sujam com o carvão das fornalhas para mover esses palácios iluminados que vencem a distância dos oceanos..." (Cidadão Zero, s.e., p. 12)

Também sofreu corte o diálogo nos momentos finais do espetáculo, em que se reforça a visão política assumida. Em tom de síntese, indica que sem os miseráveis os capitalistas morreriam de fome: "Alberto: Quer dizer então que os homens de dinheiro devem tudo aos homens sem nada? / Cidadão: - (convicto) Tudo! Sem nós os capitalistas morreriam de fome...” (Cidadão Zero, s.e., p.19)

Nesse dois trechos censurados observamos a formação de duas imagens que se polarizam, aquela dos 
endinheirados e a dos miseráveis. O que provoca a fala inflamada de Cidadão é a palavra "Miserável". A partir do momento em que a utilização dessa palavra é contestada, podemos pensar em duas noções de miséria: uma mais literal, relacionada à pobreza (miserável como pobre, mísero) e outra mais ligada ao caráter, como uma falta moral (miserável como maldito). Nesse segundo caso poderíamos substituir na peça "Miserável” por “Maldito seja!", no ímpeto de resposta da personagem Cidadão Zero.

\section{Trabalho com as imagens}

Cidadão informa logo a que veio sua intervenção e define o que quer dizer com miserável. Ele aponta o seu interlocutor, acusando-o de ser o miserável da situação. Sua definição é "aqueles que aproveitam da miséria dos humildes para enriquecer". A personagem acusa todos (em geral) os que enriqueceram às custas da pobreza de outras pessoas. E acrescenta: "o senhor que cumulou a sua fortuna com o esforço dos pequeninos...”. Assim indica que incluiu o homem que está à sua frente no grupo genérico.

A partir dessa passagem do genérico para o específico na definição da palavra "miserável" podemos observar o levantar de duas concepções de mundo sobre a miséria. Na tentativa de sua definição revela-se a dualidade da noção de miséria adotada na peça. Uma das definições é expressa: miséravel é que enriquece à custas dos outros e a outra não precisa ser dita, visto que é mais literal e é compartilhada com os leitores da peça como um pressuposto comum: miserável como pobre.

A definição de miserável proposta por Cidadão termina com a palavra "pequeninos". É ela quem irá estender a fala da personagem. Não basta definir a miséria, é necessário dizer quem sofre com ela, personalizá-la. Quando ele chega nesse ponto de sua acusação decide incluir uma digressão sobre quem são eles, aqueles que seriam mais miseráveis que esse grande miserável que é o personagem Thompson. Então na seqüência descreve-se a variedade de situações em que se encontram os homens sem nada. São situações relacionadas ao mundo urbano e ao contato com os ricos. Em cada frase dita cria-se uma dicotomia, contrapondo o que seria o mundo dos homens sem nada.

Podemos desenhar um esquema de como o diálogo segue.

1- É proferida a palavra "miserável”

MISERÁVEL - maldito seja!

miséria, mísero, mero, (mediocre)

duas noções de miséria

Cidadão recorre a uma afirmação: Miserável deveria ser

2 - Passagem do genérico para o específico

definição de quem são os verdadeiros miseráveis: aqueles que aproveitam da miséria dos humildes para enriquecer.

Quem está incluído nesse grupo: o senhor (Thompson) 
3- justificativa para incluir Thompson no grupo dos miseráveis

Ele cumulou a sua fortuna com o esforço dos pequeninos...

4- definição de quem são os pequeninos

Os pequeninos são miseráveis, mais miseráveis do que o senhor Thompson

5- descrição da situação dos pequeninos

aqueles que arriscavam a vida pendurados nos andaimes...

(frase no passado. As seguintes estão no presente)

Cria-se uma dicotomia de imagens

imagens contrastantes:

Homens sem nada $\mathbf{x}$ homens de dinheiro

\begin{tabular}{|l|l|l|}
\hline $\begin{array}{l}\text { Arriscavam a vida } \\
\text { pendurados nos andaimes }\end{array}$ & e que depois \\
\hline $\begin{array}{l}\text { Fescem às minas } \\
\text { Ficam cegos }\end{array}$ & $\begin{array}{l}\text { O brilho do ouro que circula no } \\
\text { seu bolso }\end{array}$ \\
\hline $\begin{array}{l}\text { Apunintos que de sol a sol } \\
\text { para estrair (sic) a borracha } \\
\text { dos seringais }\end{array}$ & mas que nunca & $\begin{array}{l}\text { O conforto macio das rodas dos } \\
\text { grandes packards }\end{array}$ \\
\hline $\begin{array}{l}\text { Morrem intoxicados pelas } \\
\text { tintas }\end{array}$ & & $\begin{array}{l}\text { Ornamentam a parede dos } \\
\text { "boudoirs" }\end{array}$ \\
\hline Recolhem o lixo & Fartura de todos os arranha-céus \\
\hline $\begin{array}{l}\text { Não podem comer } \\
\text { fornalhas }\end{array}$ & & $\begin{array}{l}\text { Cintilam nos dedos } \\
\text { vencem a distância dos oceanos }\end{array}$ \\
\hline
\end{tabular}


A idéia presente no contraponto das duas imagens criadas é a de que para se ter a riqueza tem de haver gente sofrendo. A riqueza não vem sem um custo. E o custo na peça está descrito nos termos do sofrimento dos pequeninos.

As imagens criadas desafiam a idéia de que a riqueza é um valor positivo em si. A comédia nos traz um conceito hoje já mais incorporado ao discurso sobre a riqueza: o ganho de alguns depende do sofrimento de outros. Tal noção pode ser associada à formação de um ideal comunista.

Podemos notar uma proximidade de alguns pontos da descrição da miséria feita por Cidadão com o Trecho Programa do Partido Comunista do Brasil [Aprovado no IV Congresso 7 a 11 de Novembro de 1954]

“Apesar destas imensas possibilidades, a situação do povo brasileiro é cada dia mais penosa e insuportável. Brasileiros morrem de fome nas estradas do Nordeste e até mesmo nos grandes centros industriais do país. A tuberculose e outras doenças matam ou inutilizam milhões de pessoas. Sem escolas nem hospitais, o povo vive na ignorância e morre ao desamparo. Vivendo num país tão rico, o povo brasileiro vegeta na miséria, em consequência da política de rapina dos monopólios norte-americanos e da dominação dos latifundiários e grandes capitalistas brasileiros". (Problemas Revista Mensal de Cultura Política, nº 64, dezembro 1954 a fevereiro de 1955)

Há um jogo paradoxal em cada frase da fala de Cidadão, em que ele contrapõe dois mundos. São duas cenas distintas. Devemos ressaltar que além dessa imagem de paralelismo existe uma imagem criada dentro de cada cena. No trecho censurado da peça há algumas palavras que reforçam o contraponto criado e criam uma imagem elas mesmas. Identificamos algumas delas em vermelho no esquema apresentado previamente. Destacamo-las novamente aqui acrescentando variações para seu uso:

Pendurados - no lugar de posicionados, localizados

Famintos - no lugar de com fome, precisando comer

de sol a sol - no lugar de diariamente

apunhalam - no lugar de acertam, cortam

intoxicados - no lugar de em contato com as tintas

fornalhas - no lugar de forno

brilho - no lugar de cor do ouro

conforto macio - no lugar de dizer apenas conforto

ornamentam - no lugar de embelezam, enfeitam

"boudoirs" - no lugar do equivalente em português, quartos

cintilam - no lugar de brilham 
palácios iluminados que vencem a distância dos oceanos - no lugar de dizer simplesmente palácios

Tais palavras são a porta de entrada de nosso estudo sobre as figuras de linguagem presentes na comédia Cidadão Zero. Elas abrem o caminho para investigarmos as duas visões de mundo que estão em jogo.

É próprio da comédia apresentar uma virada surpreendente na ação. Nesse caso, a surpresa fica por conta da idéia de que os miseráveis (pobres) são mais dignos do que os miseráveis (malditos) que se aproveitam do trabalho dos outros para benefício próprio.

\section{Conclusões}

Há sempre um jogo entre o que é dito e o que está marcado no dicurso comum como variantes ao termo usado. Essa variação fica pressuposta e é essencial para captar a imagem criada. Podemos dizer que elas abrem portas para entendermos justamente a cena criada. Essa cena já não é mais aquela do texto da peça teatral como ele vinha se encadeando. Ela é um novo ambiente criado poeticamente pelo autor e que nos permite observar um salto de sentido dado. Ele fecha interpretações sobre os temas tratados. Podemos dizer assim que o que foi cortado pode nos apresentar estereótipos através das imagens criadas.

Nossa iniciativa é de observar o tipo de imagem que está sendo censurada. Catalogar essas imagens. Observar se há reforço de um mesmo estereótipo entre as peças. Em relação à análise do corte do censor, o objetivo não é buscar resposta para a pergunta de porque o censor teria cortado o trecho em questão, mas como no texto da peça esse trecho se sobressai e essa sobressalência é reforçada pelo corte. A questão de haver o corte marca o caminho para a análise.

\section{Bibliografia:}

ARISTÓTELES. «Arte Retórica e Arte Poética». Rio de Janeiro, Ediouro, s/d.

COSTA, Cristina. «Censura em cena: teatro e censura no Brasil - Arquivo Miroel Silveira». São Paulo: EDUSP: FAPESP: Imprensa Oficial, 2006. 296 p.

DUCROT, O. « Les mots du discours». Seuil, 1980.

DUCROT, O. «Provar e dizer». São Paulo: Global, 1981.

DUCROT, O. «Dire et ne pas dire». Hermann, 1972.

DUCROT, O. «O Dizer e o Dito». Campinas, Ed. Pontes, 1987.

GOMES, Mayra R. "Palavras proibidas: um estudo da censura no teatro brasileiro". "Revista Comunicação, mídia e consumo». São Paulo, ESPM, v. 2, ano 2, nº 5, nov. 2005.

MAGALDI, Sábato; VARGAS, Maria Thereza. «Cem anos de teatro em São Paulo». São Paulo: SENAC, 2000.

MOSCA, L. S. (org.) «Retóricas de Ontem e de Hoje». 2a ed. São Paulo, Humanitas Publicações/FFLCH- 
USP, 2001 ( 1a ed, 1997,reimpr. 1999).

PERELMAN, CH. e TYTECA,L.O. «Traité de l' argumentation: la nouvelle rhétorique». 4a ed .Bruxelles. Ed. Univ. Bruxelles. 1983. Trad. port. Tratado de Argumentação: A nova retórica, S. Paulo, Martins Fontes, 1996.

PERELMAN, CH. «L'empire rhétorique : rhétorique et argumentation». Paris, Vrin,1977.Trad. port. O Império Retórico : Retórica e Argumentação. Porto, ASA, 1993. Rhétorique. Bruxelles. Ed. Univ. de Bruxelles, 1989. Trad. Port. Retóricas. S. Paulo, Martins Fontes, 1997.

PRADO, Décio de Almeida. «História concisa do teatro brasileiro». São Paulo: EDUSP: Imprensa Oficial, 1999.

SILVA, Gastão Pereira da. «Cidadão Zero». s.e.

TRINGALI, D. «Introdução à Retórica. A Retórica como Crítica Literária». S. Paulo: Duas Cidades, 1988.

\section{Mini Currículo :}

Doutoranda do Programa de Pós-graduação em Ciências da Comunicação da Escola de Comunicações e Artes da USP na área de Teoria e Pesquisa em Comunicação, mestre em comunicação e bacharel em jornalismo pela mesma Escola. andrealimberto@gmail.com. Orientadora: Profa. Dra. Mayra Rodrigues Gomes. 